\title{
Generation and size distribution of sediment eroded in a small-scale catchment of the Western Cape (South Africa)
}

\author{
N. Z. Jovanovic ${ }^{1}$, R. D. H. Bugan ${ }^{1}$, C. Petersen ${ }^{1}$, W. P. De Clercq ${ }^{2}$, \\ A. Rozanov ${ }^{2} \&$ H. Botha ${ }^{3}$ \\ ${ }^{1}$ CSIR, Natural Resources and Environment, South Africa \\ ${ }^{2}$ Department of Soil Science, University of Stellenbosch, South Africa \\ ${ }^{3}$ Department of Process Engineering, University of Stellenbosch, \\ South Africa
}

\begin{abstract}
Rainfall, runoff (overland flow), total sediments mobilized and their size distribution were measured for a number of events over three years (from 2006 to 2008) in a small-scale catchment of the Berg River (Western Cape). The aim was to develop local-scale rainfall/runoff, sediment generation and particle size distribution relationships that could be incorporated into existing hydrological catchment models for predicting erosion, transport and deposition of sediments with sorbed contaminants. The results indicated that rainfall intensity was weakly correlated to rainfall amounts $\left(\mathrm{R}^{2}=0.54\right.$ ), whilst runoff (between $12.4 \%$ and $18.2 \%$ of rainfall) was weakly correlated to the product of rainfall amount and peak intensity at two sites with different soil properties and slopes $\left(\mathrm{R}^{2}=0.29\right.$ and 0.44), depending on antecedent moisture condition, land use and management practices. Sediment concentration was inversely correlated to runoff volume. However, more runoff produced larger total sediment loads. The bulk of sediment particles mobilized via runoff water had diameters in the range between 4.76 and $15.95 \mu \mathrm{m}$ (measured with a Saturn DigiSizer 5200 particle size analyzer). Sediment size distribution was relatively uniform for all events recorded, did not depend on sediment concentration, runoff, rainfall amount and intensity, and it was similar to the texture of the soil A-horizons (source of sediments). Spatial information on soil A-horizon textural properties could therefore be used to infer the nature of sediments mobilized in the catchment.
\end{abstract}


Sediment size distribution in the catchment can be used, in conjunction with sorption data, to estimate the transport of sorbed contaminants, e.g. nutrients and pesticides. In addition, sediment size distribution can be used, in conjunction with chemical and isotopic properties of mineral particles, to trace the origin and history of sediment transport in catchments.

Keywords: erosion, overland flow, particle size distribution, sediment concentration, Western Cape.

\section{Introduction}

The most widely used erosion models are applicable to mapping spatial distribution of erosion risk or to estimating erosion rate [1]. In recent years, focus has shifted towards the development of models for predicting sediment generation, transport and deposition in catchments, in order to assess the consequences of erosion in terms of water pollution and sedimentation downstream [2]. It was recognized that control of water pollution requires an understanding of the dynamic processes occurring during individual rainfall events, the size and timing of peak discharges of water and sediment from hillslopes to rivers, as well as the nature of the sediments detached and that of the associated contaminants. Recent advances indicated that the size of mobilized soil particles depends on the two mechanisms of detachment, namely splash and wash, where particles detached through the kinetic action of raindrops are generally coarser compared to those detached through the mechanical action of overland flow [3]. The size of mobilized particles and their sorptive characteristics have implications to the transport of contaminants attached to sediments, for example nutrients and pesticides [4]. Total mobilized sediments and their particle size distribution depend on the source of sediments, i.e. the textural and aggregate properties of the soil surface. The texture of sediment particles was generally found to be finer compared to the texture of the original soil [3], or similar [5].

In this study, undertaken in the mid-reaches of the Berg river catchment (Western Cape, South Africa), the hypothesis was that the texture of sediment particles in overland flow depends mainly on the texture of parent material from where these particles were mobilized, regardless of rainfall and runoff intensities and volumes. If verified, this relation could be incorporated into existing hydrological catchment models and facilitate predictions of sediment particle sizes originating from heterogeneous areas. In order to test the hypothesis, rainfall, overland flow (referred to further as runoff), total sediments mobilized and their particle size distribution were measured for a number of events over three years (from May 2006 to October 2008) at runoff plots established in the field in a small-scale catchment. The aim was to develop rainfall/runoff, sediment generation and particle size distribution relationships that could be incorporated into existing hydrological catchment models for predicting erosion, transport and deposition of sediments with sorbed contaminants. 


\section{Material and methods}

The study site (Goedertrou farm in the Berg river catchment) is located in the Western Cape, South Africa, about $5 \mathrm{~km}$ North-East of the town of Riebeek West (fig. 1). The area is semi-arid and receives about $350 \mathrm{~mm} \mathrm{a}^{-1}$ of rainfall. Rainfall occurs mainly in winter (from April until October).

Fig. 1 shows the location of the experimental site in the Western Cape and the experimental scheme in the Goedertrou catchment ( $20 \mathrm{ha})$, on a Google Earth map. Two standard Wischmeier runoff plots $(22.3 \mathrm{~m} \mathrm{x} 2 \mathrm{~m})$ parallel to one

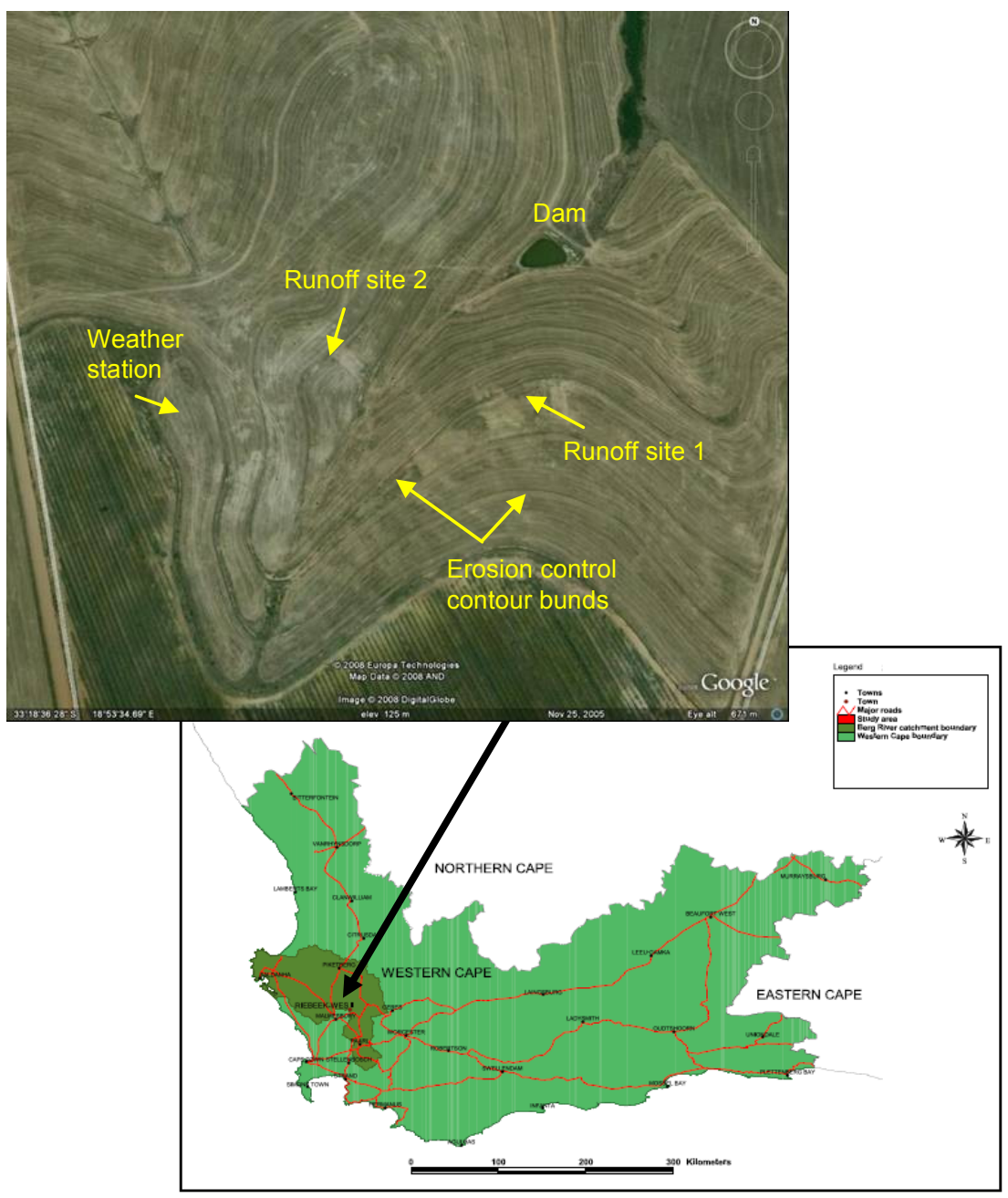

Figure 1: Location of the experimental site in the Western Cape and Google Earth map of the Goedertrou experimental catchment. 
another, were established at each runoff site 1 and 2 . The runoff sites were chosen to represent two different, but typical hydrological units, each located between two erosion control contour bunds. Site 1 was North-oriented, whilst site 2 was South-East-oriented. The soils at the two sites are also different: $0.4 \mathrm{~m}$ deep sandy clay loam Cambisol [6] overlying Malmesbury shale at site 1; deep clay loam Luvisol [6] at site 2 . The slope of site 1 is $9.1 \%$, whilst the slope at site 2 is $12.4 \%$. During 2006 and 2007, the Goedertrou farm was left uncultivated to allow re-growth of wheat and medic grass (crops planted during previous seasons) to support grazing. During 2008, the field was cultivated to wheat. An automatic weather station was installed in the catchment (fig. 1) to measure and log rainfall, solar radiation, temperature, relative humidity, leaf wetness, as well as wind speed and direction.

Measurements of rainfall, runoff, total sediments mobilized and their particle size distribution were carried out at each runoff plot (fig. 1, runoff sites 1 and 2). A flow splitter was installed in order to divide water and sediment flow from the Wischmeier runoff plots into two halves. The first portion from the flow splitter lead into a tipping bucket fitted with a magnetic switch, in order to record overland flow electronically. The tipping bucket was calibrated so that every tip corresponded to $1 \mathrm{~L}$ of water. Water volume data were collected every $10 \mathrm{~min}$ and stored with an MCS data logger (Mike Cotton Systems, Cape Town). The first flow portion was wasted thereafter. The second flow portion from the splitter lead into two sediment traps. The flow splitter was calibrated in the field to determine the exact fraction of water diverted onto the tipping bucket and sediment traps. Half of the flow was diverted onto the tipping bucket, and the other half into the sediment traps. The splitter was levelled during each field visit to ensure the calibration was correct at all times. The sediment tanks (traps) were emptied and washed after each field visit. Water volumes were also measured manually during field visits, by measuring the litres of water collected in the tanks.

The first sediment tank in the sequence was used to trap coarser sediments. Water and suspended solids then overflowed into the second sediment tank in the sequence, where finer sediments were collected. The sediment tanks were used to collect water and sediment for sampling and laboratory analysis. Water and sediment samples were taken approximately bi-weekly during the 2006, 2007 and 2008 winter seasons. Sediment and water samples were collected in $100 \mathrm{~mL}$ plastic bottles after scraping the bottom of the tanks with a clean spade.

Total sediment mass was measured in the laboratory by evaporating water from sub-samples of known volume. The remainder of the samples was then used to measure sediment particle size and distribution with a Saturn DigiSizer 5200 particle size analyzer (Micromeritics Instrument Corporation). The Saturn DigiSizer makes use of a laser beam and measures the intensity of light scattered at various angles by organic and/or inorganic particles suspended in a liquid sample. Scattered light intensities depend on particle size, shape, refractive index and wavelengths of incident light, and they are measured by a charge-coupled device that contains over one million detector elements. The particle size distribution in a water sample is calculated from the scattered light intensity 
based on the Mie theory [7], and by applying the mathematical procedure of deconvolution. Particle diameters are calculated from volumes assuming particles are spheres. The instrument measures in the particle diameter range from 0.1 to $1000 \mu \mathrm{m}$, where each order of magnitude is split into 40 pre-defined or user-defined particle size classes. Three tests were run for each sample in order to check the repeatability of results. Ultrasonic probes were not used so as to preserve aggregates and allow measurement of particles mobilized under natural conditions. For this reason, caution was exercised in handling the samples (no shaking and agitation) in order to prevent dispersion of aggregates.

Data were analyzed with a Saturn 5200 V1.09 software (Micromeritics Instrument Corporation). The software is used to enter measurement settings (analysis conditions and material properties), perform a large number of data analyses as well as to report results. It can generate a large number of reports in graphical and numerical format with different levels of detail. The output results considered in this study for each water sample were the following:

- Mode of the frequency distribution of particle diameters (calculated from volumes, assuming particles are spheres) in each sample. This output variable represented the highest frequency of occurrence of a particle size class, or the peak of frequency distribution comprising at least $5 \%$ of the distribution.

- Particle diameters representing $90^{\text {th }}, 50^{\text {th }}$ and $10^{\text {th }}$ percentiles of the cumulative volume distribution of all particles in each sample.

Rainfall at runoff sites 1 and 2 was recorded every 10 min with tipping bucket rain gauges and data were stored with MCS data loggers. The data loggers were enclosed in a box and powered via battery and solar panel. Volumetric soil water contents at sites 1 and 2 were measured electronically with Echo sensors installed at $10 \mathrm{~cm}$ and $40 \mathrm{~cm}$ soil depth and connected to Echo loggers (Decagon Devices Inc.). The purpose of the electronic measurement of soil water content was to describe soil moisture conditions antecedent to runoff events.

\section{Experimental results}

Three years of rainfall, runoff, sediment concentration and sediment size distribution data were analyzed in order to develop local-scale, empirical relationships for sediment mobilization and particle size distribution. Data included all measurements taken from 2006 to 2008, and from both sediment collection tanks. Data were processed separately for site 1 and 2, as these sites represent different soil types and slopes. Although field visits for sampling and downloading data were planned after major rainfall events, in some instances the data represented more than one rainfall event occurring in the period antecedent to sampling (period since the previous field visit and sampling). Data for some rainfall and runoff events were not available due to malfunction of data loggers, damage to equipment caused by storms and grazing cattle. In the events when rainfall data were not available from loggers installed at the runoff plot sites, records obtained from the weather station were used. 


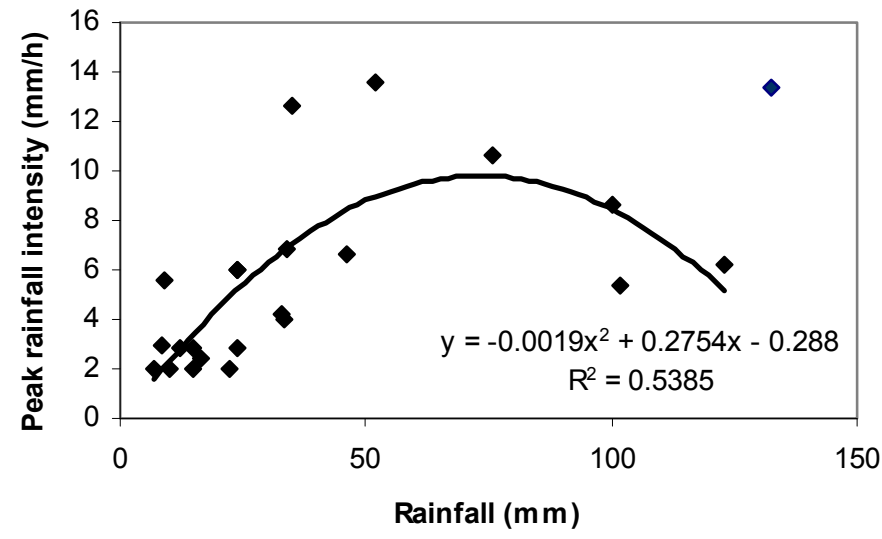

Figure 2: Relationship between rainfall and rainfall intensity (data refer to events that occurred from 2006 to 2008; number of observations $=$ 23).

A second order polynomial gave the best fit for the relationship between rainfall and peak rainfall intensity $\left(\mathrm{R}^{2}=0.54\right)$ (fig. 2). Fig. 2 gives a good representation of the nature of rainfall in the area, generally consisting of prolonged low-intensity drizzle. Highest peak rainfall intensities generally occurred for total rainfall of about $70 \mathrm{~mm}$. Frontal systems, which delivered most rainfall, generally had peak intensities $<10 \mathrm{~mm} \mathrm{~h}^{-1}$. Maximum rainfall intensity in the data set was $13.4 \mathrm{~mm} \mathrm{~h}^{-1}$. This was an exceptional event (total rainfall $=132.6 \mathrm{~mm}$ that occurred between 3 to 12 July 2008).

Runoff at site 1 was $12.4 \%$ of rainfall for all events recorded (ranging from 0 to $60.6 \%$ for individual events), whilst runoff at site 2 was $18.2 \%$ of rainfall (ranging from 0 to $69.1 \%$ ). The linear relationships between runoff and the product of rainfall amount and peak intensity are presented in fig. 3 for sites 1 and 2 . The relatively low $\mathrm{R}^{2}$ coefficients in fig. 3 are an indication that other factors may affect the relationship between runoff and rainfall, such as antecedent moisture condition, land use and management practices.

Total sediment concentrations measured in both tanks were plotted as a function of runoff volumes. The data are shown in fig. 4 for sites 1 and 2 . The inverse relationship indicates that high concentrations of sediments were generally measured when small runoff events occurred (low rainfall amounts and/or intensity). With high rainfall and runoff volumes, sediment concentrations were generally low due to dilution effects. This indicates that most sediment mobilization may occur at the beginning of a runoff event. Concentrations of sediments in runoff water were between 0 and $22.0 \mathrm{~g} \mathrm{~L}^{-1}\left(2.6 \mathrm{~g} \mathrm{~L}^{-1}\right.$ on average).

In terms of total sediment load, more eroded material was mobilized from the runoff plots during high rainfall and runoff events at both sites (fig. 5). It should be noted, however, that sediment load data in fig. 5 originated from 


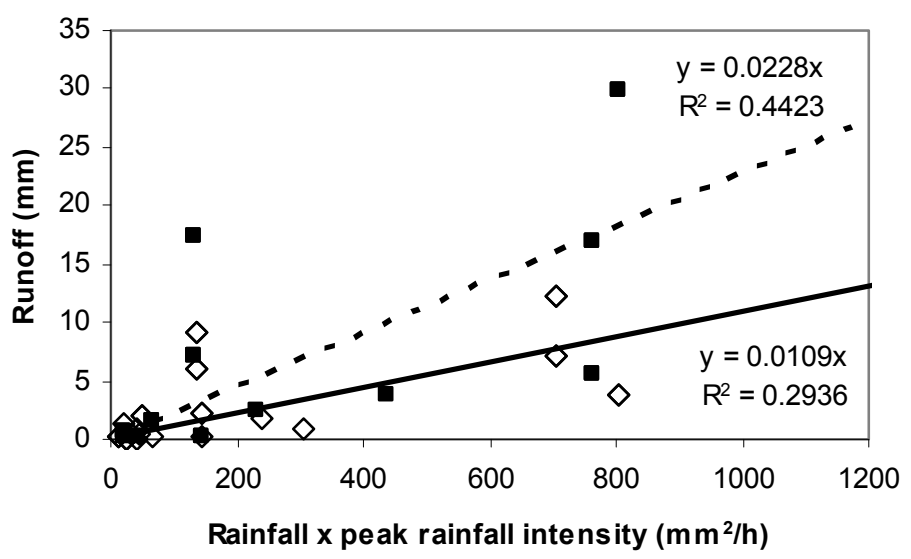

$\diamond \quad$ Site 1 - Site $2 \longrightarrow$ Site 1 - - - . Site 2

Figure 3: Relationship between runoff and the product of rainfall amount and peak intensity for site 1 (number of observations $=20$ ) and site 2 (number of observations $=15$ ) (data refer to events occurred from 2006 to 2008).

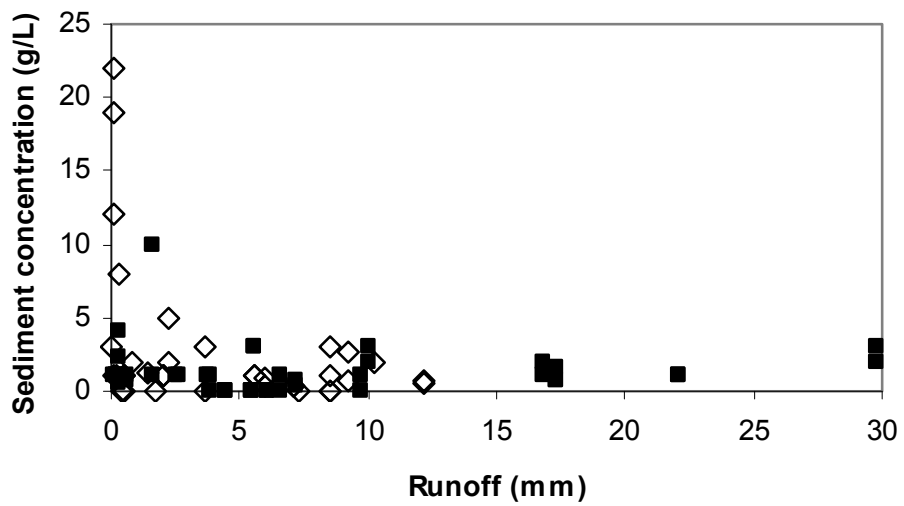

$\diamond$ Site 1 - Site 2

Figure 4: Relationship between sediment concentration and runoff for site 1 (number of observations $=36$ ) and site 2 (number of observations $=$ 39) (data refer to events occurred from 2006 to 2008). 


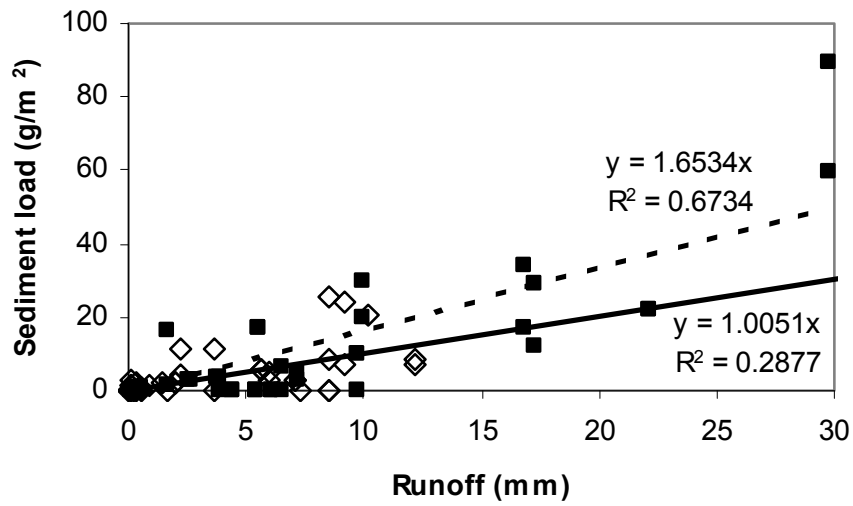

$\diamond \quad$ Site $1 \quad$ Site $2 \longrightarrow$ Site 1 - - - . Site 2

Figure 5: Relationship between sediment load and runoff for site 1 (number of observations $=36$ ) and site 2 (number of observations $=39$ ) (data refer to events occurred from 2006 to 2008).

measurements of sediments trapped in the collection tanks, representing the cumulative result of one or more events, whilst the dynamics of sediment concentrations and loads during individual runoff events was not investigated at the runoff plots. Site 2 generally produced lower sediment concentrations in runoff water (fig. 4), but more runoff and higher sediment loads compared to site 1 (fig. 5). Total annual sediment mobilization ranged between 0.02 and $0.85 \mathrm{Mg}$ $\mathrm{ha}^{-1} \mathrm{a}^{-1}\left(0.26 \mathrm{Mg} \mathrm{ha}^{-1} \mathrm{a}^{-1}\right.$ on average $)$.

The particle size analyzer outputs numerical and graphical representations of particle volume frequency percentage and cumulative finer volume percentage. The particle size analyzer was set to detect and record any peaks including at least $5 \%$ of particle size (diameter) distribution in a sample. In most cases, the peaks included $>70 \%$ of the particle size distribution. In samples where more than one peak was identified, the peak that accounted for the highest percentage of particles was considered. The peak frequency of particle diameters within a certain size class is the mode of frequency distribution of all particle sizes, and it was used as an indicator of the most frequent size of sediments mobilized for each sample.

The modes of particle diameter frequency distribution are shown in fig. 6 as a function of sediment concentrations for all samples analyzed at sites 1 and 2 . Modes of particle diameters were always in the silt range between 4.76 and $15.95 \mu \mathrm{m}$, regardless of sediment concentration and therefore rainfall amount, intensity and runoff. On average, slightly smaller modes of sediment particles were measured at site $2(9.35 \mu \mathrm{m})$ compared to site $1(9.49 \mu \mathrm{m})$ (fig. 6).

Another indicator of the size of sediments mobilized was the cumulative finer particle volume percentage over the full range of particle diameters. The shape of 


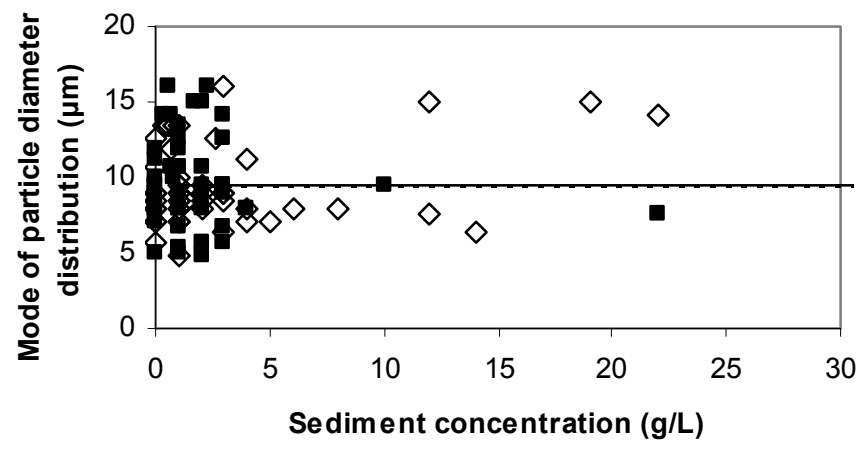

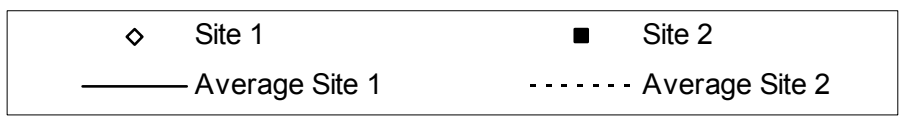

Figure 6: Relationship between mode of particle diameter frequency distribution obtained with the particle size analyzer and sediment concentration for site 1 (number of observations $=43$ ) and site 2 (number of observations $=44$ ) (data refer to events occurred from 2006 to 2008).

this curve is determined by the percentages of particles finer than a certain diameter occurring in the sample. For the purpose of this study, we considered the $90^{\text {th }}, 50^{\text {th }}$ (median) and $10^{\text {th }}$ percentiles of the cumulative particle size distribution in each sample. The results are shown in fig. 7 for sites 1 and 2 . Again, the data were spread within a narrow range regardless of sediment concentration and therefore rainfall amount, intensity and runoff. Sediment diameters mobilized from site 1 covered a slightly wider range compared to site 2 (fig. 7).

From the analyses of particle size distribution, it appeared that the size of mobilized sediment particles does not depend on the magnitude and intensity of rainfall and runoff events. The main factors were the source of sediments (texture of the top soil) and the slope of the site determining the gravity force for transport of particles of a certain size. This was confirmed through particle size analyses of soil A-horizons in the vicinity of the runoff plots. The modes of particle diameter frequency distribution of soil A-horizons were $12.67 \mu \mathrm{m}$ for site 1 and $7.55 \mu \mathrm{m}$ for site 2 . The $90^{\text {th }}, 50^{\text {th }}$ (median) and $10^{\text {th }}$ percentiles of the particle size distribution in the soil A-horizons were 75.63, 13.69 and $1.49 \mu \mathrm{m}$ for site 1 , and $77.22,6.30$ and $0.91 \mu \mathrm{m}$ for site 2, respectively. The values of modes and percentiles for soil A-horizons were therefore in the range of those measured for mobilized sediments (fig. 6 and 7). Similar results were also obtained from controlled rainfall simulation tests done on 13 different soil types in the catchment [8]. This indicated that the nature of the soil, as the source of sediments, plays a dominant role in the nature of particles mobilized. 


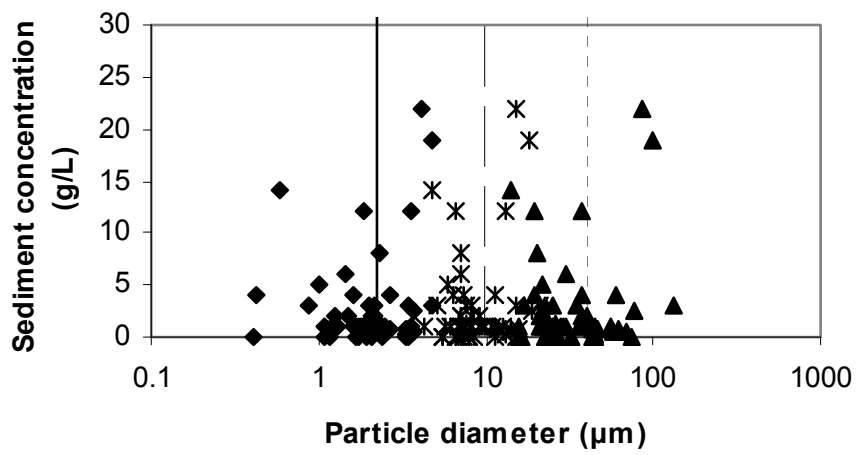

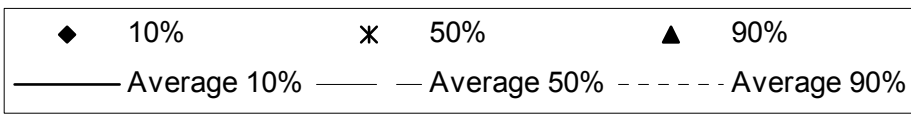

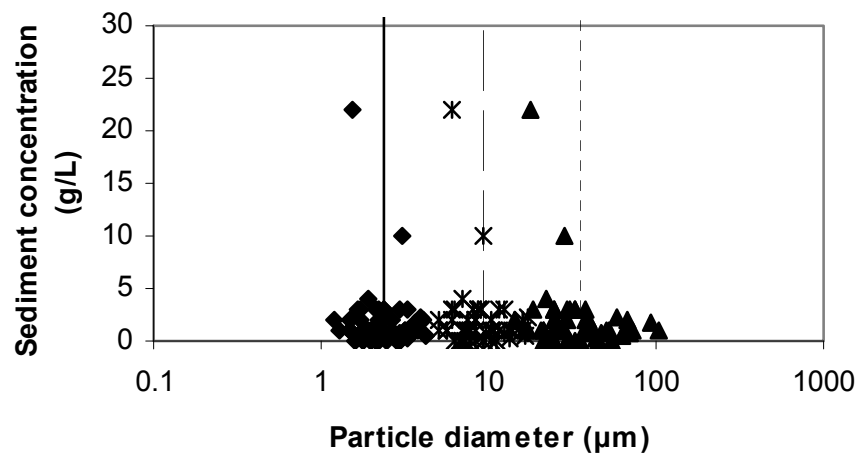

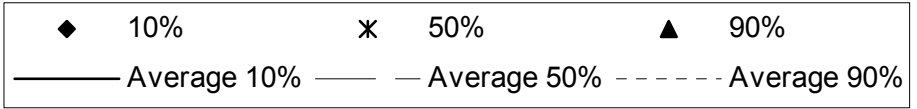

Figure 7: Relationship between $90^{\text {th }}, 50^{\text {th }}$ (median) and $10^{\text {th }}$ percentiles of the particle size distribution in runoff samples, measured with the particle size analyzer, and sediment concentration for site 1 (top graph; number of observations $=43$ ) and site 2 (bottom graph; number of observations $=44$ ) (data refer to events occurred from 2006 to 2008).

\section{Conclusions}

The following main conclusions were drawn from this study:

- Rainfall generally consists of prolonged low-intensity drizzle in the study area. Rainfall intensity was weakly correlated to rainfall amounts $\left(\mathrm{R}^{2}=0.54\right)$. 
- Runoff ranged between $12.4 \%$ and $18.2 \%$ of rainfall for all events recorded. Runoff was weakly correlated to the product of rainfall amount and peak intensity $\left(\mathrm{R}^{2}=0.29\right.$ for site 1 and $\mathrm{R}^{2}=0.44$ for site 2$)$.

- An inverse relationship was observed between sediment concentration and runoff volume. However, more runoff volume produced larger total sediment loads. Total annual sediment mobilization ranged between 0.02 and $0.85 \mathrm{Mg} \mathrm{ha}^{-1}$ $\mathrm{a}^{-1}\left(0.26 \mathrm{Mg} \mathrm{ha}^{-1} \mathrm{a}^{-1}\right.$ on average).

- The bulk of sediment particles mobilized via runoff water had diameters in the range between 4.76 and $15.95 \mu \mathrm{m}$. Particle size distributions resembled the texture of the soil A-horizons, regardless of sediment concentration, runoff, rainfall amount and intensity.

The findings of this study open up opportunities for a wide range of applications. For example, spatial information on soil A-horizon textural properties could be used to infer the nature of sediments mobilized in large-scale catchments. This information, along with the empirical relationships between rainfall, runoff and sediment load found in this study, can be incorporated into existing hydrological catchment models, and facilitate the estimation of total sediment load in the Berg river catchment. Similarly, the texture of sediments deposited downstream of their source could be used, in conjunction with chemical and isotopic properties of mineral particles, to identify areas in the catchment that are prone to erosion. Knowledge of sediment particle size distribution can also be used to estimate transport of sorbed pollutants (e.g. nutrients or pesticides) via sediment particles, provided sorption coefficients are known.

\section{Acknowledgements}

The authors wish to acknowledge the funding of the Water Research Commission (Pretoria, South Africa) and the contributions of M. Fey (University of Stellenbosch, Department of Soil Science), T. Scheepers, J. Twahirwa, I. Harun, A. Ali, G. Frantz, P. Meyer and B. Lawrence (University of the Western Cape, Department of Earth Sciences).

\section{References}

[1] Wischmeier, W.H. \& Smith, D.D., Predicting Rainfall Erosion Losses, USDA Agricultural Handbook No. 537, 1978.

[2] Shirazi, M.A., Boersma, L., Johnson, C.B. \& Haggerty, P.K., Predicting physical and chemical water properties from relationships with watershed soil characteristics. Journal of Environmental Quality, 30, pp. 112-120, 2001.

[3] Issa, O.M., Bissonais, Y.L., Planchon, O., Favis-Mortlock, D., Silvera, N. \& Wainwright, J., Soil detachment and transport on field- and laboratory-scale interrill areas: Erosion processes and the size-selectivity of eroded sediment. Earth Surface Processes and Landforms, 31(8), pp. 929-939, 2006. 
[4] Wu, Q., Riise, G., Lundekvan, H., Mulder, J. \& Haugen, L.E., Influences of suspended particles on the runoff of pesticides from an agricultural field at Askim, SE-Norway. Environmental Geochemistry and Health, 26(2), pp. 95-302, 2004.

[5] Beuselinck, L., Steegen, A., Govers, G., Nachtergaele, J., Takken, I. \& Poesen, J., Characteristics of sediment deposits formed by intense rainfall events in small catchments in the Belgian Loam Belt, Geomorphology, 32(1-2), pp. 69-82, 2000.

[6] FAO, World Reference Base for Soil Resources, Food and Agricultural Organization of the United Nations, Rome, Italy, 1998.

[7] Mie, G., Beiträge zur Optik trüber Medien, speziell kolloidaler Metallösungen, Annalen der Physik (Leipzig), 330, pp. 377-445, 1908.

[8] De Clercq, W.P., Fey, M.V. \& Jovanovic, N., Land Use Impacts on Salinity in Western Cape Waters. Water Research Commission Report No. K5/1503: Pretoria, South Africa, 2010. 